\title{
AN ASSESSMENT OF USING VARIABLE BLADE PITCH FOR MOORED OCEAN CURRENT TURBINE FLIGHT CONTROL
}

\author{
James H. VanZwieten 1,a \\ jvanzwi@fau.edu
}

\author{
Parakram Pyakurel a \\ ppyakurel2014@fau.edu
}

\author{
Tri Ngo b \\ csultan@vt.edu
}

\author{
Cornel Sultan $\mathrm{b}$ \\ tdn12aoe@vt.edu \\ Nikolaos I. Xiros ${ }_{c}$ \\ nxiros@uno.edu
}

${ }^{1}$ Corresponding author

${ }^{a}$ Florida Atlantic University, 777 Glades Road, Boca Raton, FL, USA, 33431

${ }^{\mathrm{b}}$ Virginia Tech, 460 Old Turner St., Blacksburg, VA, USA, 24061

${ }^{c}$ University of New Orleans, 2000 Lakeshore Drive, New Orleans, LA, USA, 70148

\begin{abstract}
This paper investigates the possibility of using active individual blade pitch control for positioning moored ocean current turbines within an array. Using a numerical simulation of a representative ocean current turbine it is shown that harmonic blade oscillations with amplitudes of $1.5^{\circ}$ can be used to displace an ocean current turbine laterally by a distance equal to one rotor diameter, when the mooring cable length is approximately 30 times the diameter of the rotor blade. For current flow directions that would result in a downstream turbine operating in the wake of an upstream system at a distance of 10 diameters, this technique could be used to reduce the power loss of the downstream system from about 50\% (caused by the reduced flow speed available in the turbine wake) to the $1.2 \%$ power loss associated with the suggested control approach.
\end{abstract}

Keywords: Ocean Current Turbine; Ocean Current Energy; Marine Renewable Energy; InStream Hydrokinetic; Individual Blade Pitch Control; Moored Turbine Control

\section{INTRODUCTION}

Strong ocean currents can be found along the western boundaries of the world's oceans, with some of the best candidates for potential hydrokinetic electricity production being the Gulf Stream, Kuroshio Current, and Agulhas Current. Figure 1 shows a numerical estimate of the three year averaged Kinetic Energy Flux (KEF) globally [1]. While this numerical model has been shown to significantly under predict the average KEF in several areas [2], it highlight the primary region where this resource is located. The possibility of harnessing this resource using Ocean Current Turbines (OCT)s has been a topic of multiple studies over the past several decades $[3,4,5,6,7]$. Several organizations have been developing devices to create electricity from this resource [8], with recent testing of experimental system conducted in both a tow tank [9] and offshore [10,11]. 


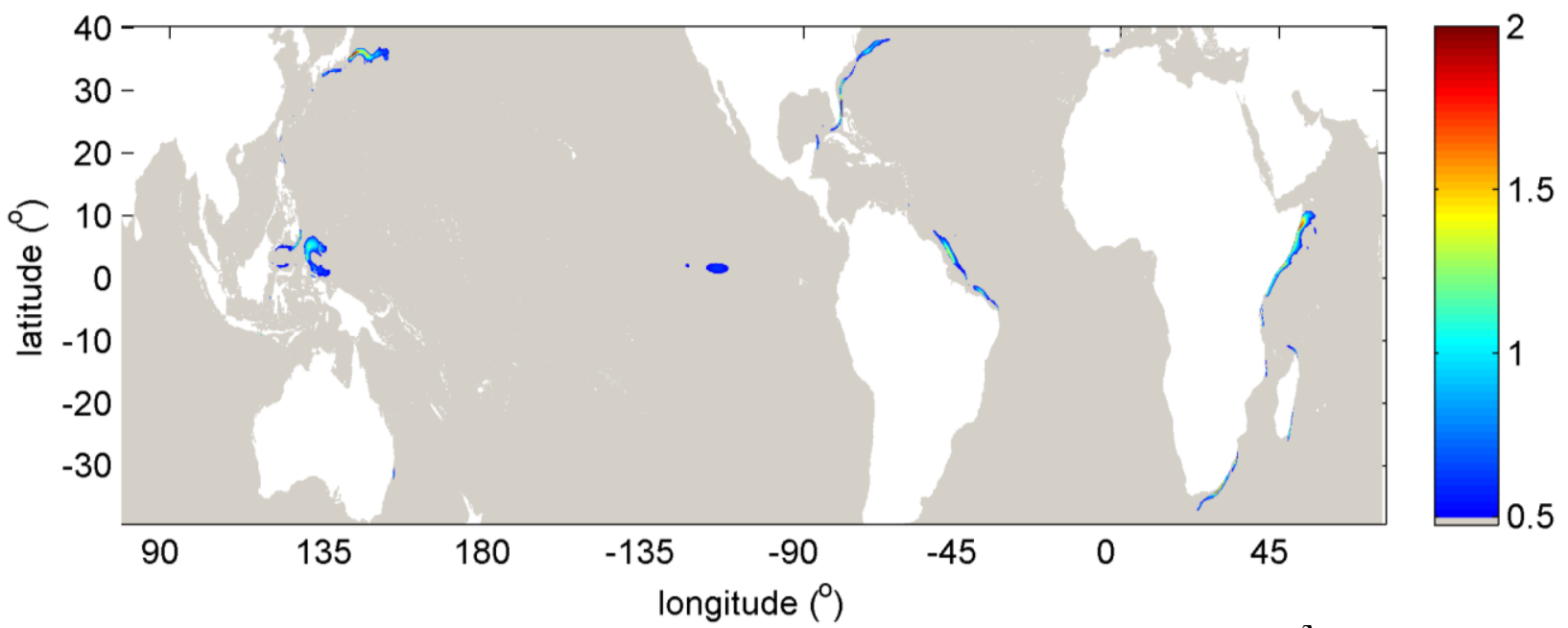

Figure 1. HYCOM-calculated area with time-averaged kinetic energy flux in $\mathrm{kW} / \mathrm{m}^{2}$ that are greater than $0.5 \mathrm{~kW} / \mathrm{m}^{3}$ at the sea surface (2009-2011).

As technologies advance towards commercial scale, control techniques will be needed to optimally locate these devices for long term operation. Off the Southeast Florida coast, future commercial OCTs will likely be moored in water depths from 300 to $400 \mathrm{~m}$. These systems will likely operate within the top $100 \mathrm{~m}$ of the water column, where the current is measured to be the strongest and most consistent. Figure 2 shows a cross section of the average KEF off Southeast Florida at $27^{\circ} \mathrm{N}$. This cross-section highlights the importance of operating near the sea surface, as well as the water depths where this resource is located.

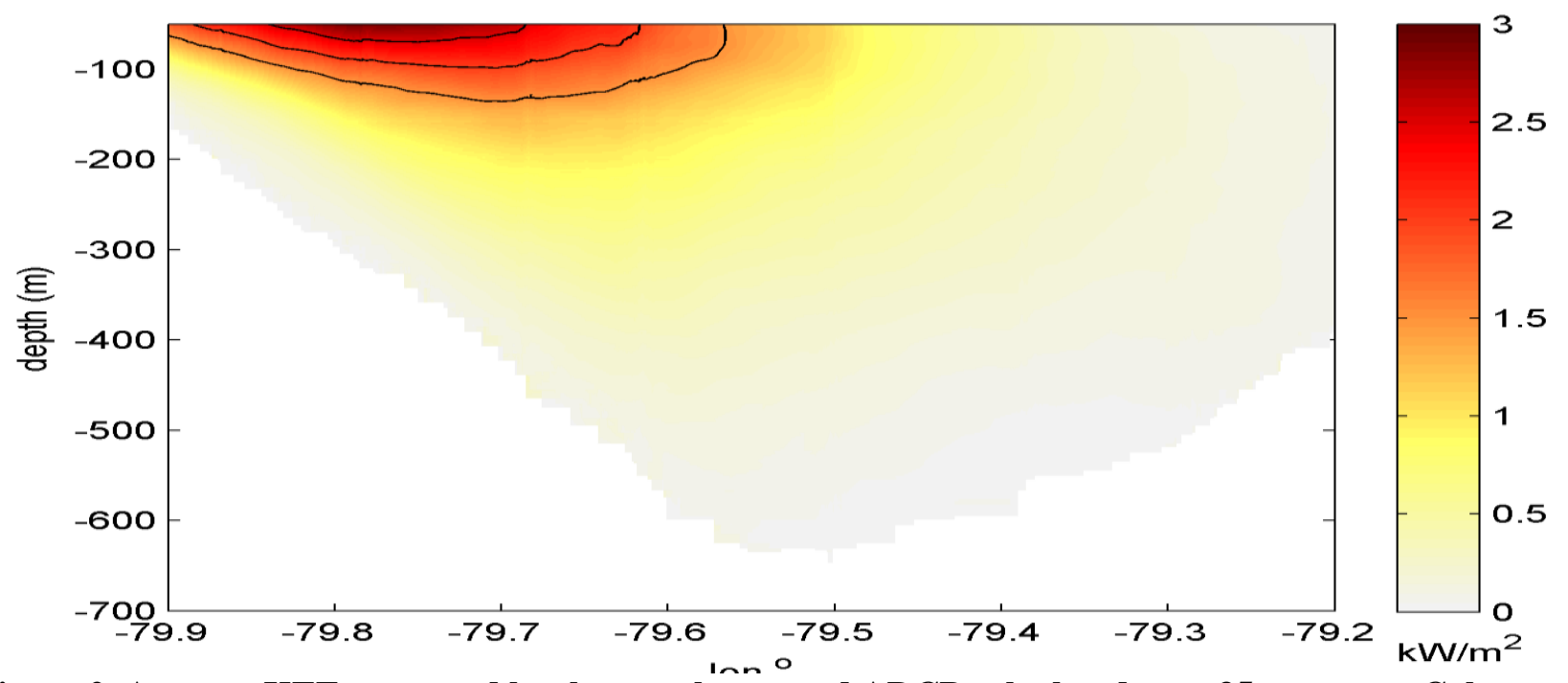

Figure 2. Average KEF measured by the vessel mounted ADCP calculated over 35 transects. Color scale units are in $\mathrm{kW} / \mathrm{m}^{2}$ and contour lines are drawn at $1.5,2.0$ and $2.5 \mathrm{~kW} / \mathrm{m}^{3}$.

When deployed in commercial scale arrays, multiple turbine will likely be moored in relatively close proximity to each other with the downstream devices located such that they are not in the wake of systems that are immediately upstream for the most common flow direction (Figure 3.Left). However, measurements have shown that the Gulf Stream, which is likely the most unidirectional ocean current resource [1], still has a flow direction standard deviation at a depth of 50 meters that is between $6-10^{\circ}$ [12]. Without active flight control device mooring systems will align themselves with the flow, leading to situations where downstream devices could be operating in the wake of upstream systems (Figure 3.Right). 


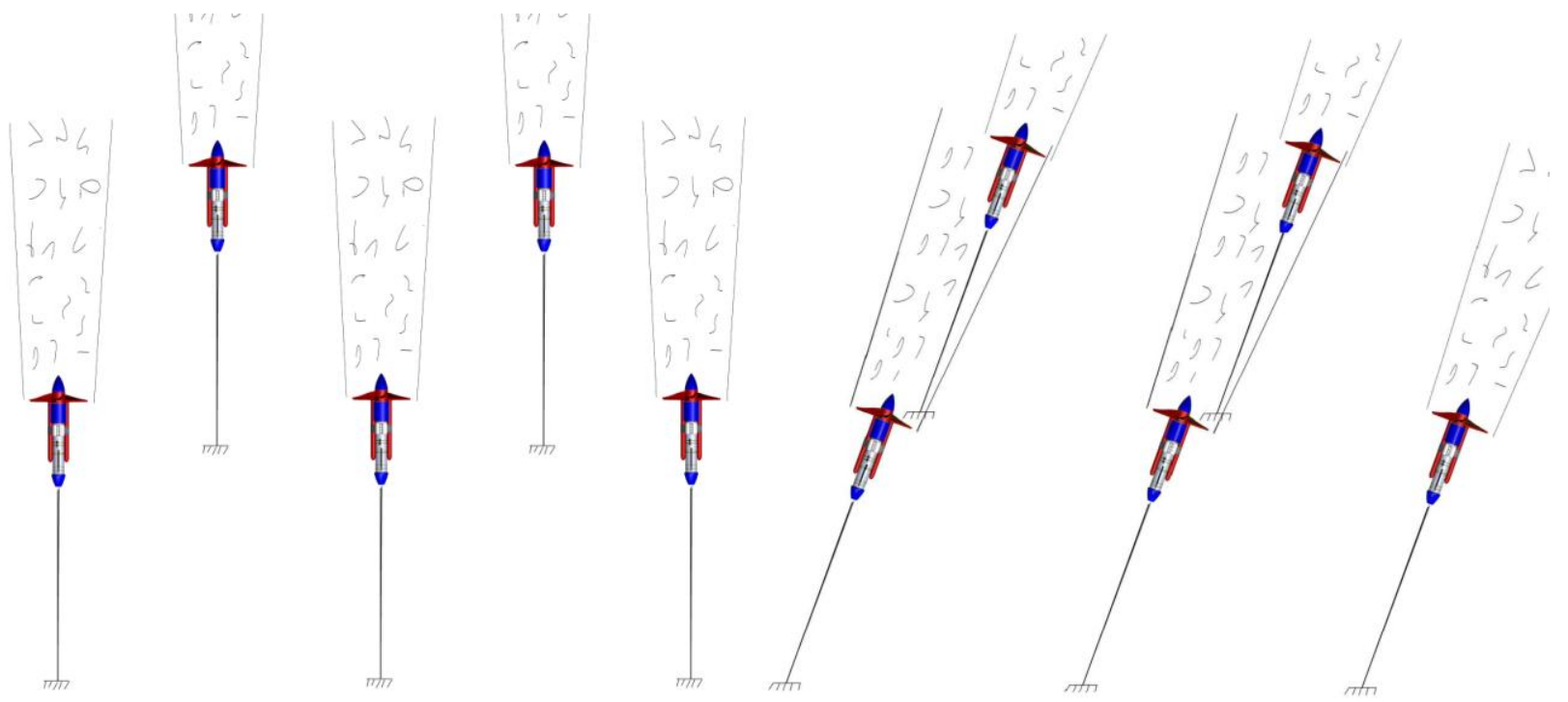

Figure 3. Diagram showing a potential ocean current turbine configuration for an array. Turbine alignments and wake fields are depicted for the primary flow direction (left) and a flow direction deviation from the primary flow direction (right). Please note that the mooring cables are not drawn to scale.

Many different commercial designs have been proposed for OCTs, with several proposing the use of axial flow rotors that have several similarities to the rotors used on most commercial wind turbines. For systems with individual blade pitch control, rotor blade root angles can be individually varied such that lateral forces can be generated if properly controlled (much the same way as helicopters are controlled). Also note that well established technology in helicopter blade control exists that can be transferred to turbine blade control. This type of control can potentially be used to create lateral displacements of turbines that can move them out of the wake of upstream devices, leading to increased power production and decreased loadings without the need for additional control surfaces.

In this paper a variable speed, pitch to feather hydrodynamic rotor design is utilized as a representative rotor for commercial ocean current turbines. A numerical model of this rotor is attached to a representative OCT design and numerically simulated to predict the turbine response to rotor blade actuation. Harmonic independent blade actuation is then applied to this system and its open loop response is evaluated. Energy production gains associated with moving out of the wake of upstream devices are then compared with the power losses associated with this type of control.

\section{NUMERICAL OCT SIMULATION}

\subsection{Site Specific Flow Measurements}

Ocean current measurements were made off Southeast Florida (Lat: $26^{\circ} 04.3^{\prime} \mathrm{N}$, Lon: $79^{\circ}$ $\left.50.5^{\prime} \mathrm{W}\right)$ using a bottom mounted acoustic Doppler current profiler over a 13 month period from February 2009 - March 2010 [4]. These measurements show that the mean current speed at a depth of $25 \mathrm{~m}$ was $1.6 \mathrm{~m} / \mathrm{s}$, with a range between 0.4 and $2.5 \mathrm{~m} / \mathrm{s}$. At a depth of $25 \mathrm{~m}$, the mean measured kinetic energy flux was $2.32 \mathrm{~kW} / \mathrm{m}^{2}$, yielding a mean kinetic energy flux over the swept area of a $20 \mathrm{~m}$ diameter rotor of $730 \mathrm{~kW}$. A histogram of the current speed measured at this depth is presented in Figure 4. These data were used in the rotor optimization presented in this paper. 


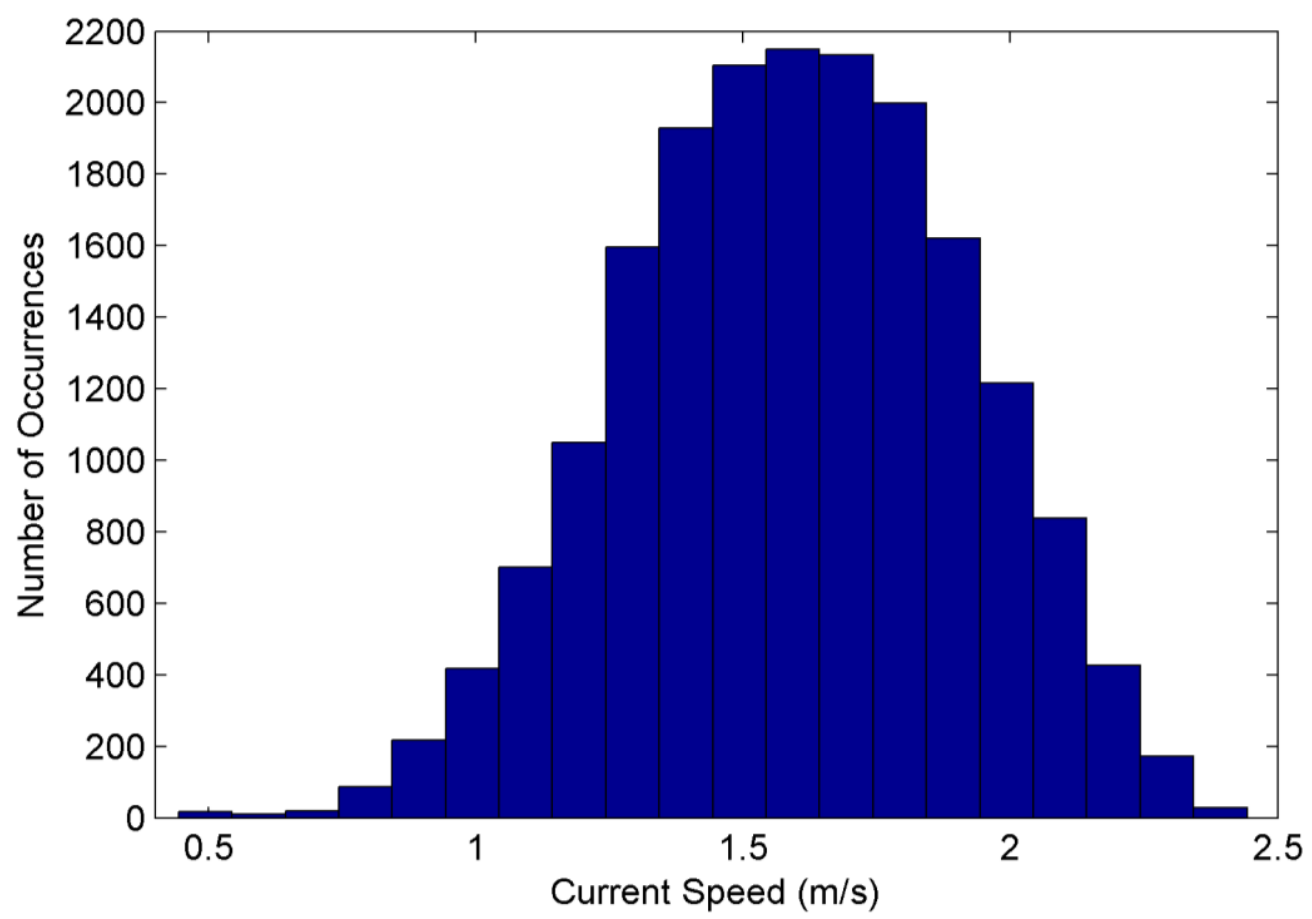

Figure 4. Histogram of the current speed at a depth of $25 \mathrm{~m}$ measured offshore Ft. Lauderdale, FL over a period from February 2009 - March 2010.

\subsection{Rotor Blade Hydrodynamic Design}

To design a representative rotor blade for this analysis the HARP_Opt version 2.00.00 optimization routine is utilized [13]. This program uses a genetic algorithm routine to maximize average energy production. Airfoil shapes evaluated for this rotor blade design came from the UICI Applied Aerodynamics Group's list of airfoil shapes [14] and the National Renewable Energy Laboratory's S-series airfoil page [15]. From these sources the following 16 different optimization input sets were selected, each containing from 1-6 airfoil shapes, and independently evaluated: 1) AH-94-W, 2) BW3, 3) USNPS4, 4) FX-77-W(s), 5) FX-79-W, 6) FX-83-W, 7) AH-93-W, 8) FX-77-W, 9) FX-84-W, 10) MH, 11) SG6050 and SG6051, 12) SG6041 and SG6040, 13) SG6042 and SG6040, 14) SG6043 and SG6040, 15) S835, S833, and S834, and 16) S823 and S822. A more detailed discussion of these airfoil sets is provided in [16].

Coefficients of lift and drag were found for each airfoil shape using XFOIL (v. 6.96). A Reynolds number of 1,000,000 was utilized and coefficients were calculated for angles of attack spanning approximately $-20^{\circ}$ to $+30^{\circ}$. This coefficient range was extrapolated using the Viterna method [17] over the required range of $-180^{\circ}$ to $+180^{\circ}$ using AirfoilPrep (v. 2.2) [18]. HARP_Opt settings used to determine the "optimal" rotor blade design for each airfoil set are presented in Table 1.

Table 1. Utilized HarpOpt settings.

\begin{tabular}{|l|l|}
\hline Rotor diameter & $20 \mathrm{~m}$ \\
\hline Hub diameter & $3 \mathrm{~m}$ \\
\hline Pre-cone angle & $0^{\circ}$ \\
\hline Twist range & $0-40^{\circ}$ \\
\hline Chord length range & $0.1-3.0 \mathrm{~m}$ \\
\hline Number rotor blades & 3 \\
\hline Rated power & $700 \mathrm{~kW}$ \\
\hline Operating speed approach & Variable speed \\
\hline
\end{tabular}




\begin{tabular}{|l|l|}
\hline Power shedding approach & Pitch to feather \\
\hline RPM range probability & $2.0-12.0$ RPM \\
\hline $\begin{array}{l}\text { Flow Fig. } 4 \\
\text { distribution }\end{array}$ & $1026 \mathrm{~kg} / \mathrm{m}^{3}$ \\
\hline Fluid density & $1.032 \times 10^{-6} \mathrm{~m}^{2} / \mathrm{s}$ \\
\hline Kinematic viscosity
\end{tabular}

The predicted average shaft power produced from the optimized rotor designs range from 287.5-302.1 kW (Figure 5). These results predict that the optimized FX-83-W rotor outperformed all other optimized designs, producing on average $2.0 \mathrm{~kW}$ more power than the FX-84-W hydrofoil set, and $3.0 \mathrm{~kW}$ more power than the AH-93-W hydrofoil set. This power output equates to $41.5 \%$ of the kinetic energy flux at this location being converted to shaft power. If this rotor is operated to produce up to $700 \mathrm{~kW}$, for a system with the same power rating, then the system will be operated at a capacity factor of $43.2 \%$.

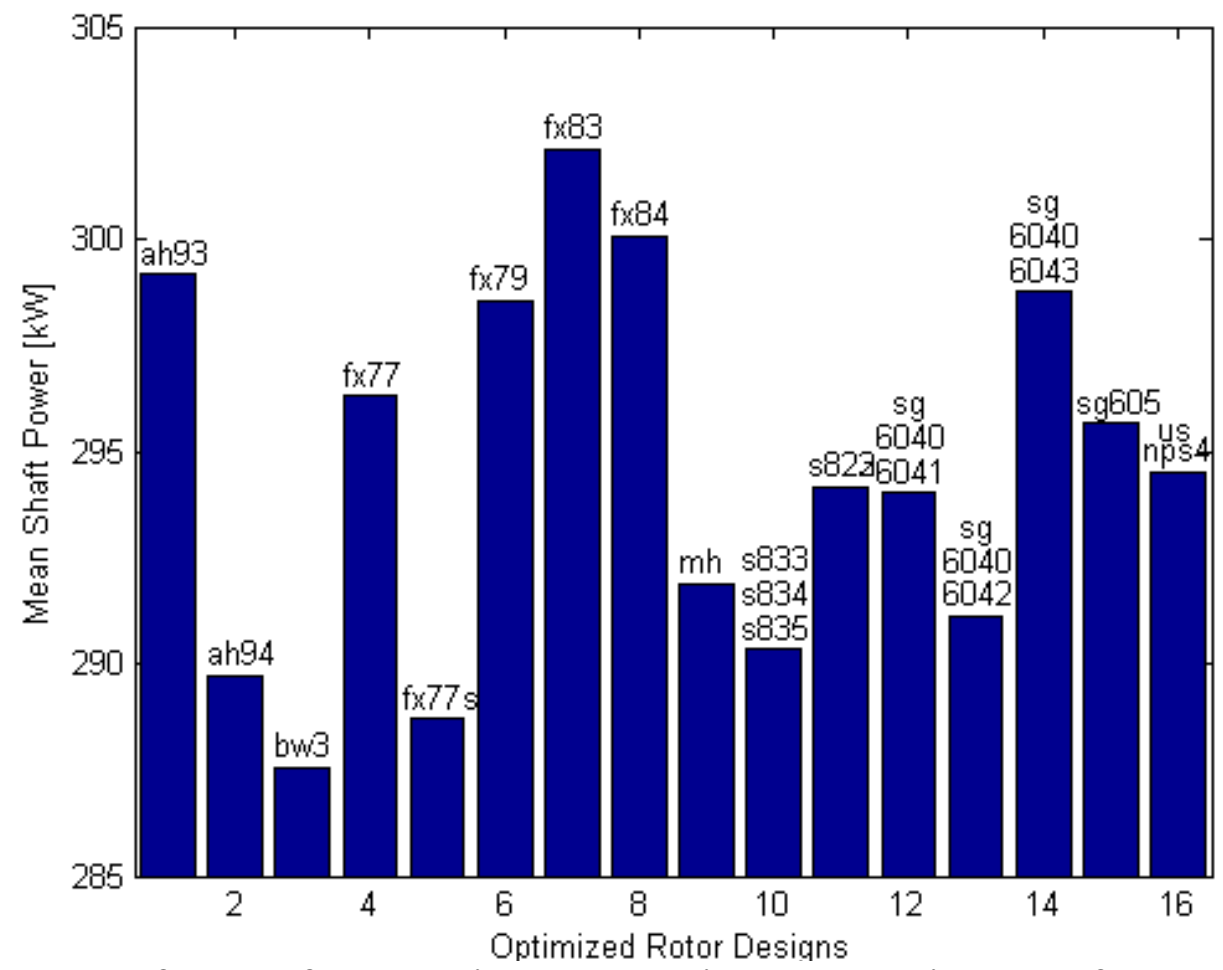

Figure 5. Average shaft power for the optimal rotor design created using each of the evaluated sets of airfoils. These predictions are made for a variable-speed and variable-pitch rotor evaluated in the current speeds measured at a depth of $25 \mathrm{~m}$.

Because of its predicted power output, the optimized FX-83-W rotor design was selected as the representative rotor design utilized in this study. This rotor has a blade twist that ranges from $18.51^{\circ}$ near the hub to $0.61^{\circ}$ at the tip. The chord of each rotor blade ranges from $1.093 \mathrm{~m}$ near the hub to $0.246 \mathrm{~m}$ at the tip, while the thickness ratio ranges from $98.5 \%$ near the hub (nearly circular) to $10.8 \%$ at the tip. The power, torque, RPM, and blade root pitch are presented as a function of flow speed in Figure 6. The scaled flow probability and free stream kinetic power distribution curves are included in these plots to add context. 


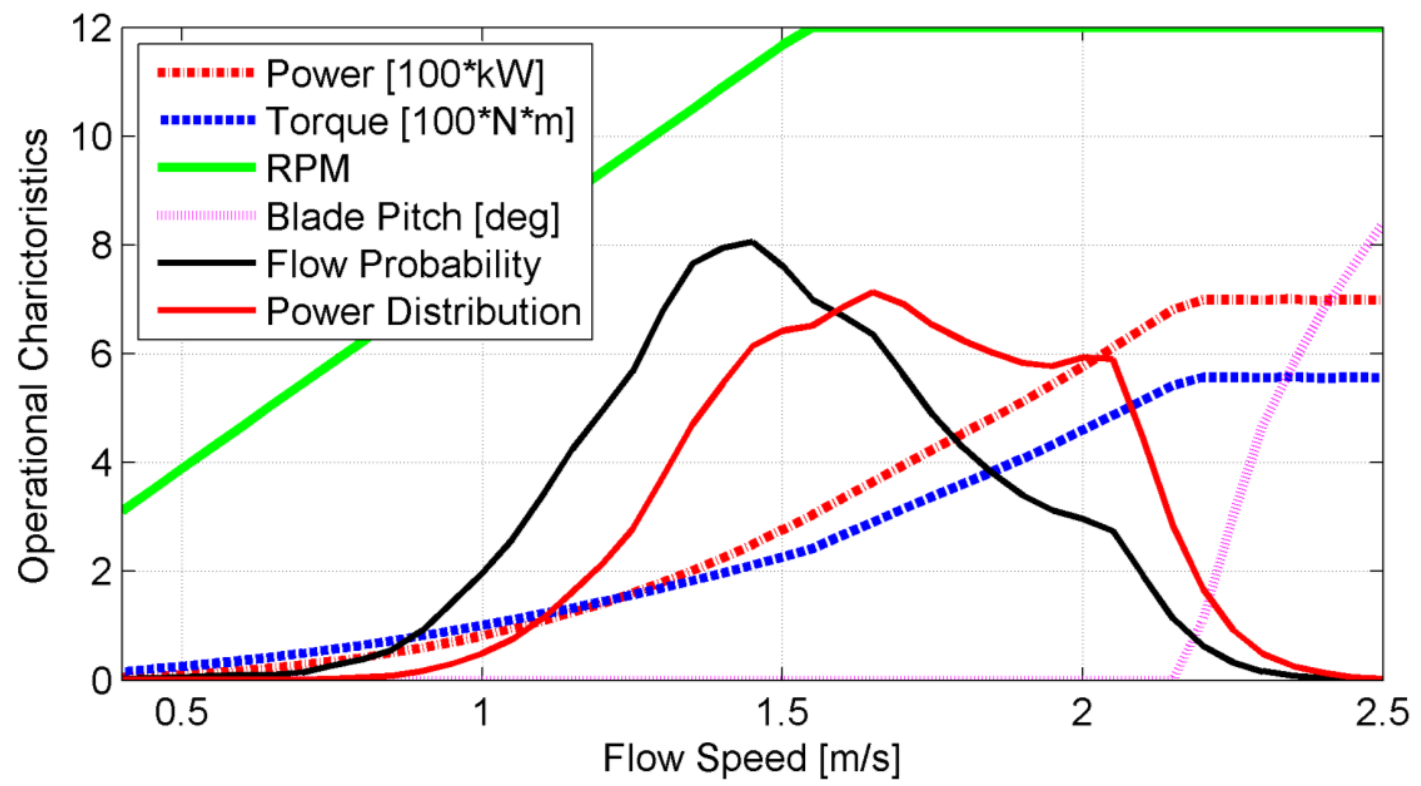

Figure 6. Power, thrust, RPM, scaled flow probability, and scaled kinetic energy distribution presented as a function of free stream velocity. These predictions of performance for the optimized FX-83-W rotor design.

\subsection{OCT System Description}

The OCT mechanical design utilized in this study is based on a nearly neutrally buoyant conceptual design developed by the Southeast National Marine Renewable Energy Center (SNMREC) [19] (Figure 7). While significantly re-designed before construction and at sea testing [10], this design variant was chosen because its performance has been numerically quantified in previous studies [20, 23, 24, 25]. This system is a horizontal axis OCT that was originally sized for a $3 \mathrm{~m}$ diameter rotor blade. However, in this study all of the length, area, volume, and inertial properties are scaled from those in [20] by $20 / 3,(20 / 3)^{2},(20 / 3)^{3}$, and $(20 / 3)^{3}$ and the rotor is replaced by the $20 \mathrm{~m}$ diameter variable pitch rotor design discussed earlier. The envisioned testing configuration for this OCT is attaching it, via a cable, to a flounder plate, which is connected to a main mooring line that runs from a surface buoy to the sea floor. A similar configuration is used in this study.

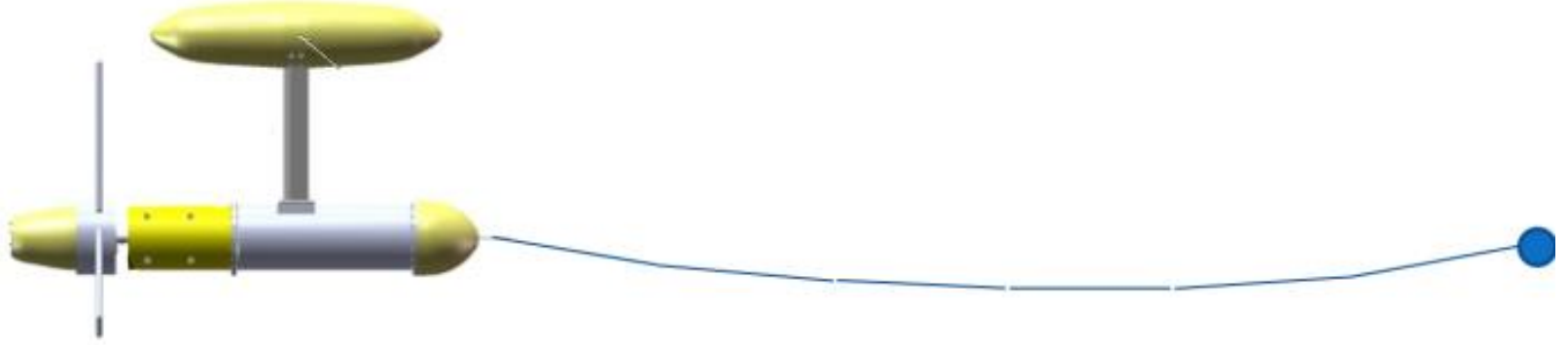

Figure 7. The SNMREC's neutrally buoyant research ocean current turbine design and associated mooring cable that are simulated in this paper. Please note that the rotor is not accurately drawn in this rendering and that the cable is not drawn to scale.

\subsection{Numerical Simulation}

This section provides an overview of the numerical simulation approach used for the full moored OCT simulation. This numerical simulation models the turbine system, as well as the cable that attaches it to the flounder plate (Figure 7). The utilized hydrodynamic and cabling 
numerical modeling approaches are described in detail by [20] and briefly summarized here, followed by a discussion of the modeling changes made to accommodate individual blade pitch. Hydrodynamic forces that act on the rotor, main body that houses the generator and rotor shaft, two buoyancy compensations modules, and tow cable elements, are calculated at each time step. These hydrodynamic forces, along with gravity, buoyancy, and elastic cable forces, are utilized to calculate the net forces and moments on the OCT. The seven-degree of freedom (DOF) motion of the turbine is calculated as suggested by [20], except with different inertial properties. A finite element lumped mass cable model is used for the $607 \mathrm{~m}$ long cable that attaches the turbine to the flounder plate. The motion of these cable nodes are calculated at each time step, adding to the degrees of freedom for the numerically modeled system.

Changes to the numerical simulation approach that was presented in [20], beyond scaling and implementing a new rotor blade design, are those required to simulate a rotor with individually controlled blade pitch. These changes include: incorporating the individual blade root angles into the angle of attack calculations for each rotor blade. The impact of the individually controlled blade pitch angles are also accounted for when calculating the reduced flow rate caused by the extraction of energy from the flow. The momentum modeling approach originally presented by [20] calculates the impact of energy extraction on a grid that covered the swept area of the rotor blade. The impeded flow values at these mesh points were updated each time step using the local undisturbed flow speed, the momentum reduction estimates from the previous time step, and the blade hydrodynamic characteristics. For the updated variable pitch rotor model utilized in this project the blade root angle values utilized for each grid point calculation are set to match the root angle of the last rotor blade that passed, at the time of its passing.

\section{OPEN LOOP CONTROL INPUTS}

To evaluate the flight control achievable using individual blade pitch control, open loop simulations are run where the root angles of the individual rotor blades are harmonically oscillated as a function of azimuth angle about the blade root angle that produces maximum power when the system is operating at the optimal tip speed ratio for a steady axial flow. A similar blade oscillation approach has been previously evaluated for reducing the cyclic blade loadings on wind turbines caused by wind shear [21], with the utilized transformation matrix commonly used for DC to AC electrical power conversion [22]. The harmonic blade oscillations from this base value are defined by:

$$
\left[\begin{array}{l}
\gamma_{1} \\
\gamma_{2} \\
\gamma_{3}
\end{array}\right]=\left[\begin{array}{cc}
\sin (\alpha+4 \pi / 3) & \cos (\alpha+4 \pi / 3) \\
\sin (\alpha+2 \pi / 3) & \cos (\alpha+2 \pi / 3) \\
\sin (\alpha) & \cos (\alpha)
\end{array}\right]\left[\begin{array}{l}
\gamma_{a} \\
\gamma_{b}
\end{array}\right]
$$

where $\alpha$ is the azimuth angle of rotor blade \#3 with respect to the top of the turbine (in a turbine fixed frame), $\gamma_{a}$ and $\gamma_{b}$ are constants used to set the magnitude and direction of the harmonic oscillations, and $\gamma_{1}, \gamma_{2}, \gamma_{3}$ are the blade root angle deviations from their base value for rotor blades \# 1,2,3 respectively. The root angles of the three blades over one rotor rotation is shown in Figure 8 for $\gamma_{a}=0$ and $\gamma_{b}=3$ as an example. 


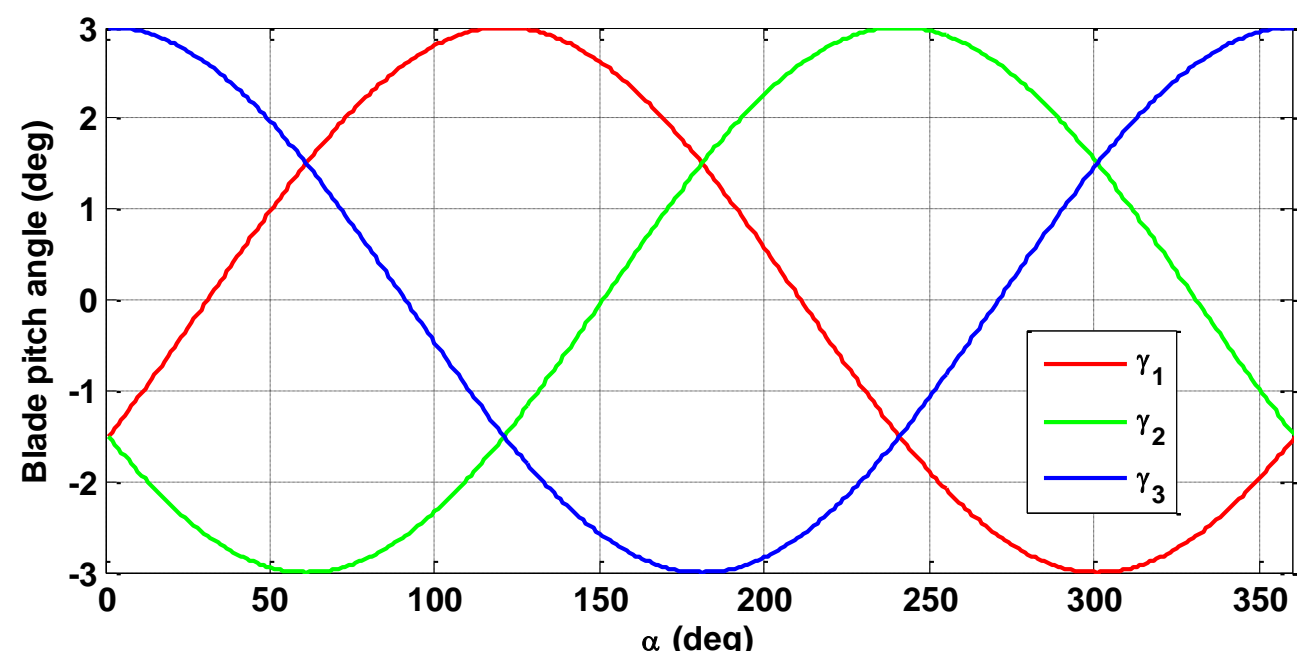

Figure 8. Root angle of the three rotor blades as a function of rotor azimuth angle.

To control rotor blade rotation a standard fixed gain Region 2 control scheme commonly utilized for variable speed turbines [26]:

$\tau=k \omega^{2}$

is utilized, where $\tau$ is the electromechanical shaft torque, $k$ is a fixed gain that is based on the turbines maximum coefficient of power and the tip speed ratio where this coefficient of power is obtained, and $\omega$ is the rotor rotational velocity in $\mathrm{rad} / \mathrm{s}$.

\section{RESULTS}

To evaluate the displacement of the turbine perpendicular to the oncoming current, numerical simulations are run where the independent harmonic blade actuation (Eq. 1) are utilized with amplitudes of $1.5^{\circ}$ and $3.0^{\circ}$ (i.e. $\sqrt{\gamma_{a}^{2}+\gamma_{b}^{2}}=1.5^{\circ}$ and $3.0^{\circ}$ ). These simulation runs are conducted for a constant (in space and time) flow velocity of $1.6 \mathrm{~m} / \mathrm{s}$.

The equilibrium displacements of the turbine, from its operating location without the use of harmonic blade oscillation, are presented in Figure 9. These displacements were calculated by running the simulation until the device reaches an equilibrium location. Results presented in the YZ-plane with this coordinate system being defined where: $\mathrm{X}$ is horizontal and into the flow, $\mathrm{Z}$ is perpendicular to the flow and vertically downwards, and $\mathrm{Y}$ following the right hand rule. These results suggest that equilibrium horizontal displacements of $21 \mathrm{~m}$ and $40 \mathrm{~m}(1.05$ and 2.0 rotor diameters; 3.5 and $6.6 \%$ of the mooring line length) can be obtained in the horizontal direction for oscillation amplitudes of 1.5 and $3.0^{\circ}$ respectively. Vertical displacements however are much more limited at $2.8 \mathrm{~m}$ and $5.4 \mathrm{~m}(0.14$ and 0.27 rotor diameters; 0.5 and $0.9 \%$ of the mooring line length) for the same oscillation amplitudes of 1.5 and $3.0^{\circ}$ respectively. It is worth noting that that vertical turbine displacements will likely be achievable using variable buoyancy systems and therefore the minimal vertical displacement are not of great concern. 


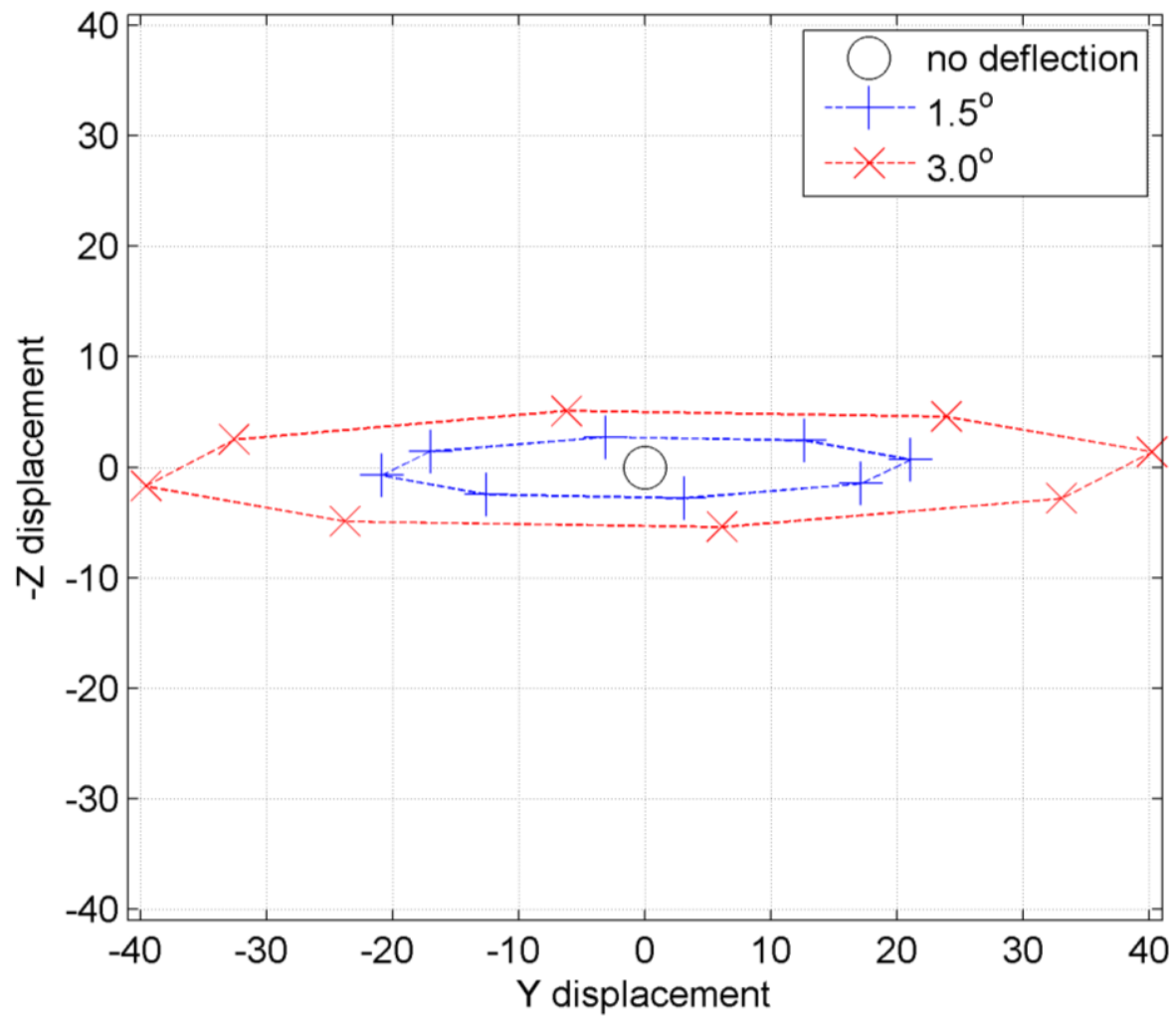

Figure 9. Turbine displacements achieved when harmonic blade pitch is utilized.

These lateral motions are achieved with an associated power production loss. After the OCT transitions to its equilibrium location in a homogenous flow, reduced mean power production values of $4.6 \mathrm{~kW}$ and $19.0 \mathrm{~kW}$ are associated with the achieved lateral displacements of $21 \mathrm{~m}$ and $40 \mathrm{~m}$ for $1.5^{\circ}$ and $3.0^{\circ}$ harmonic displacements. These are equivalent to $1.2 \%$ and $5.0 \%$ reductions in power production respectively.

The transient response of the turbine systems to this control input is rather sluggish, with maximum lateral turbine speeds being around 3\% and $6 \%$ of the flow speed for harmonic oscillation amplitudes of $1.5^{\circ}$ and $3.0^{\circ}$ respectively. Lateral transient turbine speed is presented in Figure 10 for the simulations where nearly horizontal displacements are achieved in the $+\mathrm{Y}$ direction $\left(\gamma_{a}=0\right.$ and $\gamma_{b}=1.5$ and 3.0). This show that the transient speeds during these maneuvers reach 0.05 and $0.1 \mathrm{~m} / \mathrm{s}$ for oscillations amplitudes of 1.5 and $3.0^{\circ}$ respectively. 


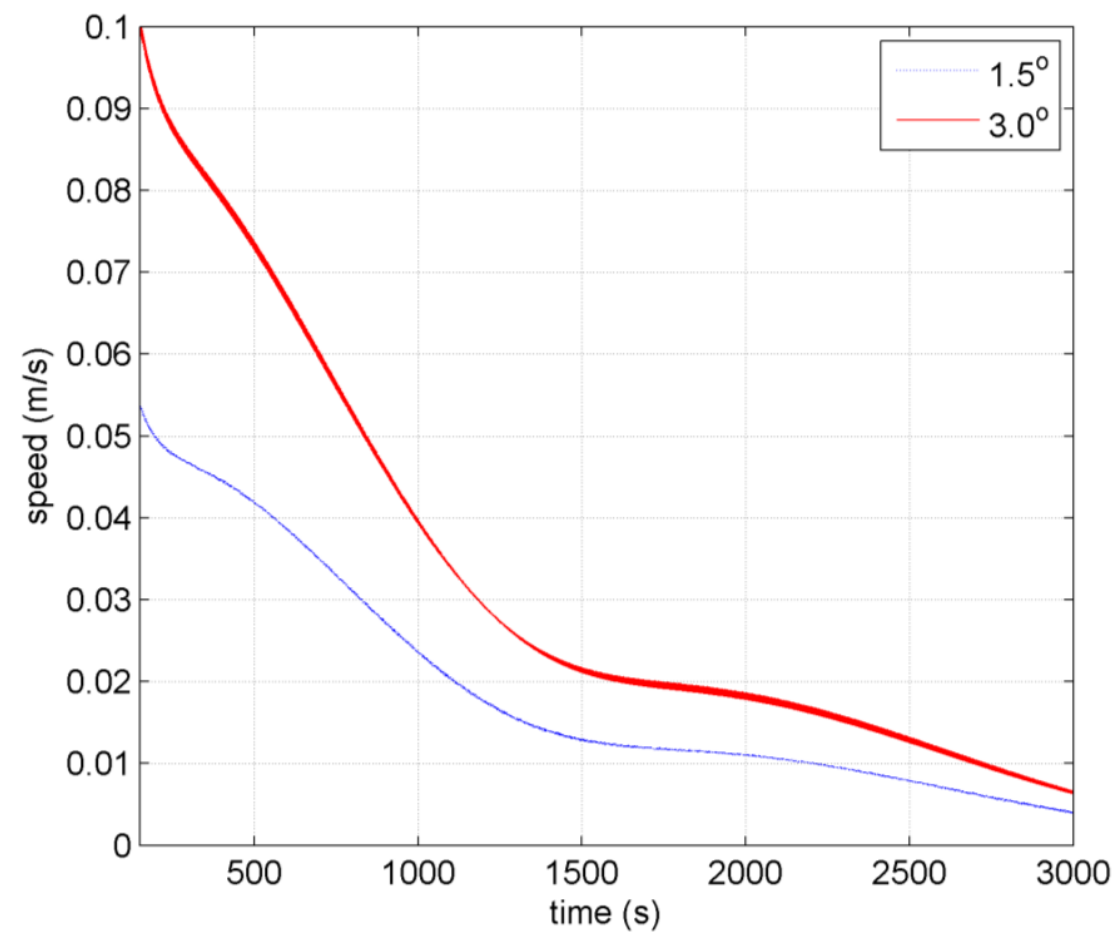

Figure 10. Turbine speed achieved for $\gamma_{a}=0 ; \gamma_{b}=1.5^{\circ}$ and $\gamma_{a}=0 ; \gamma_{b}=3.0^{\circ}$ respectively when transiting from the equilibrium location achieved with $\gamma_{a}=\gamma_{b}=0$.

\section{DISCUSSION}

To put the power production costs associated with using harmonic blade oscillations into perspective, they are compared with the power production cost that would be associated with a downstream turbine operating in the wake of upstream systems (the scenario shown in Figure 3.Right). To do this, estimates of the radius of disturbed water 10 diameters downstream from a turbine are used to determine the maximum horizontal displacement required for a device to move out of the wake of an upstream system. The power production costs associated with achieving this displacement is compared with the reduced power production associated with a system operating in the wake of an upstream device at a distance of 10 diameters downstream.

An experimental study of wake properties of marine current turbine was conducted in water tunnel with a turbine model of rotor diameter of $700 \mathrm{~mm}$ [27]. For an ambient turbulence intensity of $8 \%$, the flow recovered to near free-stream velocity at a radial distance (crosswise direction) of about 0.8 diameters, at a location 9 diameters downstream. Recovery to a free stream velocity was also measures at a radial distance of about 1 diameter for a downstream distance of 10 diameters when the ambient turbulence intensity was $11.7 \%$ [28]. Based on these studies it can be approximated that if devices with a rotor diameter of $20 \mathrm{~m}$ are initially co-axial and separated by 10 hydraulic diameters in the downstream direction, the downstream device will need to be displaced laterally by $20 \mathrm{~m}$ to operate out of the wake of the upstream system. Using the control technique presented earlier, this can be achieved by using harmonic blade oscillations with an amplitude of $1.5^{\circ}$ on the downstream system, without requiring any modifications to the operation of the upstream device. This would result in a power production reduction of about $1.2 \%$ for the downstream device when compare to operating in the ambient flow, with no power reduction experienced by the upstream system.

For the experiment with a turbine rotor diameter of $700 \mathrm{~mm}$ and ambient turbulence intensity of $8 \%$ the axial center-line wake velocity had recovered to about $80 \%$ of free-stream velocity at a distance of 9 diameters downstream [27]. An experiment in the recirculating water channel in the Institute of Fluid Dynamics at ETH Zurich measured that wake velocity had recovered to about 
$65 \%$ of free-stream velocity at 8 diameters downstream [29]. From these experiments it can be estimated that at 10 diameters downstream the centerline wake will be at around $80 \%$ of its free stream velocity. Since hydrodynamic power is approximately a function of velocity cubed, a device operating in the wake of an upstream device at a distance of 10 diameters will produce roughly $51 \%$ of the power produced by a system operating in an undisturbed flow. This power loss is much greater than the approximately $1.2 \%$ power loss associated with using individual blade pitch control to operate out of the wake of the upstream system.

\section{CONCLUSIONS}

This paper presented a numerical model of a representative ocean current turbine with a variable pitch $20 \mathrm{~m}$ diameter rotor that is attached to a mooring cable with a length of $607 \mathrm{~m}$. A harmonic independent blade actuation scheme is introduced that can be used to move the device laterally by approximately one rotor diameter by varying the root angles of the blades with an amplitude of $1.5^{\circ}$. This was achieved at a power production cost of $1.2 \%$, which is much less than the approximately $51 \%$ power production loss associated with operating 10 diameters directly downstream from a device of equal size.

Future work will look into more advanced control solutions where individual blade control is not restricted to simplistic harmonic blade actuations. Additionally, shaft torque control will be modified to maximize extracted power when individual blade actuations are utilized. Finally, these control solutions will be evaluated using a numerical ocean current farm model that will model the hydrodynamic interactions between devices within an ocean current turbine farm.

\section{ACKNOWLEDGEMENTS}

We would like to thank the National Science Foundation (NSF) and specifically the Energy, Power, Control and Networks (EPCN) program for their valuable ongoing support in this research within the framework of grant ECCS-1308168 'Collaborative Research: Optimized Harvesting of Hydrokinetic Power by Ocean Current Turbine Farms Using Integrated Control'. SNMREC is supported by the U.S. Department of Energy and the State of Florida.

\section{REFERENCES}

[1] J.H. VanZwieten Jr., A.E.S. Duerr, G.M. Alsenas, H.P. Hanson, Global ocean current energy assessment: an initial look, in: 1st Marine Energy Tech. Symp. (METS13) hosted by the 6th annual Global Marine Renew. Energy Conf., April 10-11, 2013, Washington D.C.

[2] J.H. VanZwieten Jr., I. Meyer, G.M. Alsenas, Evaluation of HYCOM as a tool for ocean current energy assessment, in: 2nd Marine Energy Tech. Symp. (METS14) hosted by the 7th annual Global Marine Renew. Energy Conf., April 10-11, 2014, Washington D.C.

[3] W.S. Von Arx, H.B. Stewart, J.R. Apel, The Florida Current as a Potential Source of Useable Energy, in: Mac Arthur Workshop on the Feasibility of Extracting Usable Energy from the Florida Current, Feb 27-Mar 1, 1974, Palm Beach Shores, Florida

[4] A.E.S. Duerr, M.R. Dhanak, Hydrokinetic Power Resource Assessment of the Florida Current, in: MTS/IEEE Oceans Conf., September 20-23, 2010, Seattle, WA, no. 100528-20

[5] W.A. Venezia, A.M. Clark, (1995) Turbine Under Gulf Stream (TUGS) Overview of an Energy Source Potential, Sea Technology 36(9) (1995)

[6] R.E. Raye, Characterization study of the Florida Current at 26.11 North Latitude, 79.50 West Longitude for ocean current power generation, (M.S. Thesis), Florida Atlantic Univ., (2002) Boca Raton, FL,

[7] J. VanZwieten, F.R. Driscoll, A. Leonessa, G. Deane, Design of a Prototype Ocean Current Turbine - Part I: Mathematical Modeling and Dynamics Simulation, Ocean Engineering 33(1112) (2006) 1485-1521 
[8] Department of Energy, "Marine and hydrokinetic technology database" http://en.openei.org/wiki/Marine_and_Hydrokinetic_Technology_Database (Accessed January 4, 2016)

[9] H. Swales, D. Coakley, S. Gupta, S. Way, Stability and loads validation of an ocean current turbine, in: $2^{\text {nd }}$ Marine Energy Tech. Symp. (METS14) hosted by the 7th annual Global Marine Renew. Energy Conf., April 15-18, 2014, Seattle, WA

[10] Southeast National Marine Renewable Energy Center. http://snmrec.fau.edu/ (Accessed: July, 22, 2014)

[11] W.D. Bolin, Ocean stream power generation: unlocking a source of vast, continuous, renewable energy, in: $2^{\text {nd }}$ Marine Energy Tech. Symp. (METS14) hosted by the 7th annual Global Marine Renew. Energy Conf., April 15-18, 2014, Seattle, WA http://www.globalmarinerenewable.com/images/pdf/METS_PAPERS_VII/71-Bolin.pdf

(Accessed January 4, 2016)

[12] J.H. VanZwieten, W.E. Baxley, G.M. Alsenas, I. Meyer, M. Muglia, C. Lowcher, J. Bane, M. Gabr, R. He, T. Hudon, R. Stevens, A.E.S. Duerr, Ocean current turbine mooring considerations, in: Offshore Tech. Conf., May 4-7, 2015, Houston, Texas, no. OTC-25965-MS

[13] D.C. Sale, HARP_Opt User's Guide, https://nwtc.nrel.gov/HARP_Opt Last modified 27July-2010; (Accessed January 4, 2016)

[14] UIUC Applied Aerodynamics Group, (2011) “Airfoil Coordinates Database” Department of Aerospace Engineering, University of Illinois at Urbana-Champaign, http://www.ae.illinois.edu/m-selig/ads/coord_database.html\#F (Accessed 2011)

[15] NWTC External Website (Unofficial), Wind Turbine Airfoil List, National Renewable Energy Laboratory, http://wind.nrel.gov/airfoils/AirfoilList.html Last modified 21-October-2009 (Accessed 22-February-2011)

[16] J.H. VanZwieten Jr., C.M. Oster, A.E.S. Duerr Design and analysis of a rotor blade optimized for extracting energy from the Florida Current" in: ASME 2011 Int. Conf. on Ocean, Offshore, and Arctic Eng., Rotterdam, Netherlands, June 19-24, 2011, no. OMAE2011-49140

[17] L.A. Viterna, D.C. Janetzke, Theoretical and experimental power from large horizontal-axis wind turbines, in: 5th Biennial Conf. and Workshop on Wind Energy, Washington D.C., Oct. 57,1981

[18] C. Hansen, "AirfoilPrep" NWTC Design Codes, Available: http://wind.nrel.gov/designcodes/preprocessors/airfoilprep/ Last modified 09-March-2010 (Accessed 22-February-2011)

[19] F.R. Driscoll, G.M. Alsenas, P.P. Beaujean, S. Ravenna, J. Raveling, E. Busold, C. Slezycki, A 20 kW open ocean current test turbine, in: MTS/IEEE Oceans Conf., September 1518, 2008, Quebec City, Canada, no. OCEANS.2008.5152104

[20] J.H. VanZwieten, N. Vanrietvelde, B. Hacker, Numerical simulation of an experimental ocean current turbine, Oceanic Engineering, 38(1) (2013) 131-143

[21] E.A. Bossanyi, Individual Blade Pitch Control for Load Reduction, Wind Energy, 6 (2003) $119-128$

[22] R.H. Park, Two-reaction theory of synchronous machines, generalized method of analysis Part 1, in: Winter Conv. of the A.I.E.E., New York, NY, January 28-February 1, 1929, 716-727

[23] M.T. Young, Design and analysis of an ocean current turbine performance assessment system, (M.S. Thesis), Florida Atlantic University, 2012

[24] J.H. VanZwieten Jr., M.T. Young, K.D. von Ellenrieder, Design and analysis of an ocean current turbine performance assessment system, in: IEEE Oceans Conf., Hampton Roads, Virginia, October 14-19, 2012, no. 120530-005 
[25] N.I. Xiros, J.H. VanZwieten, C. Sultan, V. Tzelepis, Power take-off control of in-stream hydrokinetic turbines, in: ASME 2014 Dynamic Systems and Control Conf., October 22-24, 2014, San Antonio, Texas, no. DSCC2014-6247

[26] K.E. Johnson, L.J. Fingersh, M.J. Balas, L.Y. Pao, Methods for increasing region 2 power capture on a variable speed wind turbine, in: $23^{\text {rd }}$ ASME Wind Energy Symp., Reno, Nevada, January 5-8, 2004

[27] F. Maganga, G. Germain, J. King, G. Pinon, E. Rivoalen, Experimental characterisation of flow effects on marine current turbine behaviour and on its wake properties, IET Renewable Power Generation, 4(6) (2010)

[28] T. Blackmore, W.M.J. Batten, A.S. Bahaj, Influence of turbulence on the wake of a marine current turbine simulator, Proc. of R. Soc. of Lond. 470(2170) (2014)

[29] H. Xiao, L. Duan, R. Sui, T. Rosgen, Experimental investigations of turbulent wake behind porous disks, in: 1st Marine Energy Tech. Symp. (METS13) hosted by the 6th annual Global Marine Renew. Energy Conf., April 10-11, 2013, Washington D.C. 